\title{
PREVALENCE OF MALARIA PARASITES AMONG BLOOD DONORS IN SELECTED HOSPITALS OF DHAKA CITY
}

\author{
HOQUE MM ${ }^{1}$, ISLAM MA ${ }^{2}$, BEGUM HA ${ }^{3}$, RAHMAN M${ }^{4}$, RAHMAN SM ${ }^{4}$, AL MAMUN MA ${ }^{5}$, \\ CHOWDURY FS ${ }^{6}$, HOSSAIN MA ${ }^{7}$
}

\begin{abstract}
Blood serves as a vehicle for transmission of blood-borne pathogens and transfusion-associated malaria is a potentially serious complication. The present study was conducted to determine the prevalence of Malaria parasites in blood donors. Total of 400 blood donors were selected from Transfusion Medicine Department of two teaching institutes, Bangabandhu Sheikh Mujib Medical University (BSMMU) and National Institute of Diseases of Chest and Hospital (NIDCH), Dhaka between the period of 1st January and 30th April 2003. The blood samples were examined under microscope by thick film in the laboratory of Institute of Epidemiology, Disease Control \& Research (IEDCR), Dhaka. The socio-demographic characteristics of the study subjects show that 304 (76\%) blood donors were males and 96 (24\%) of them were females. The malaria parasites were found in $3(0.76 \%)$ donors out of 400 donors. From 400 donors, 52 (13\%) donors had the history of residence/ travel in malaria zone and 348 (87\%) had no such history. The 8 (15\%) out of 52 who had the history of residence/ travel in malaria zone had previous history of malaria and had taken anti-malarial drug. It can be concluded from the present study that there is some risk of transmission of malaria parasites in blood transfusion among the voluntary and professional blood donors in Bangladesh.
\end{abstract}

Key words: Malaria parasites, Blood donors, Thick film.

J Dhaka Med Coll. 2008; 17(2) : 94-97.

\section{Introduction:}

Blood transfusion used in the management of emergencies involving patients with lifethreatening conditions. Although this process is a life-saving venture, it also poses problems if not well managed, as there is always a risk of immunological adverse reactions and transmission of other blood-borne pathogens ${ }^{1}$. Malaria can be transmitted by inoculation of blood from infected donor to patient ${ }^{2}$. It is well established that all four human malaria parasites ( $P$. falciparum, $P$. vivax, $P$. ovale and $P$. malariae) may be transfusion-transmitted ${ }^{3}$.

The transmission of malaria by blood transfusion was one of the first recorded incidents of transfusion-transmitted infection. On a global scale malaria remains one of the most common transfusion-transmitted infections ${ }^{4}$. The transmission of malaria by blood transfusion is a serious risk, as the diagnosis of malaria in the recipient is unexpected and this is often missed ${ }^{5}$. In endemic areas transmission of malaria by blood transfusion poses a real threat ${ }^{6}$.

Transfusion induced malaria was first reported in 1911, but still no definite measures have ruled out its transmission through blood transfusion, especially in endemic areas. Transfusion malaria is particularly common

1. Assistant Professor, Department of Transfusion Medicine, Dhaka Medical College, Dhaka.

2. Associate Professor, Department of Transfusion Medicine, BSMMU, Dhaka.

3. Associate Professor, Department of Transfusion Medicine, Dhaka Medical College, Dhaka.

4. Assistant Professor, Safe Blood Transfusion Programme, Dhaka Medical College, Dhaka.

5. Senior Medical Officer, Bangladesh Institute of Health Sciences (BIHS) Hospital, Darussalam, Dhaka.

6. Assistant Registrar, Department of Transfusion Medicine, Dhaka Medical College, Dhaka.

7. Assistant Professor, Department of Medicine, Tairunnessa Memorial Medical College, Gazipur.

Correspondence : Md. Mazharul Hoque (Tapan) 
in countries where blood donation has become a commercial transaction ${ }^{7}$. The malaria parasites can survive in red blood cells at refrigerator temperatures $\left(+2{ }^{\circ} \mathrm{C}\right.$ to $\left.+6^{\circ} \mathrm{C}\right)$ for days or weeks lead to the original exclusion of all blood donors who could represent a potential $\mathrm{risk}^{8}$. In endemic countries the problem is far greater as the majority of donors may be potentially infected with malaria parasites. One possible option for reducing transfusion-transmitted malaria is laboratory screening 9 . The simple deferral of donors may be wasteful and can eventually erode the donor base. More systematic care needs to be directed towards blood screening. Although, antigen detection by monoclonal antibodies is recommended as a routine screening procedure by blood transfusion services in malaria endemic countries ${ }^{4}$, in countries like Bangladesh it may not be practical.

Following WHO sponsored campaigns of prevention and more effective treatment, the incidence of malaria was greatly reduced in the year 1950-1960. But since 1970 there has been resurgence. Now malaria has re-emerged as a major Public Health problem in the tropical countries $^{10}$.

In Bangladesh, large number of blood is collected from the professional blood donors and most of this blood is not screened for malaria parasites. Use of unscreened blood keeps the patients at risk of acquiring malaria by blood transfusion. Following the 1971 ban of DDT in Bangladesh, malaria cases have increased steadily. Malaria persists as a major health problem in the thirteen south-eastern and north-eastern districts of Bangladesh ${ }^{11}$.

\section{Materials and Methods:}

The present cross sectional study was conduced in the Transfusion Medicine Department of BSMMU and NIDCH between the period of $1^{\text {st }}$ January, 2003 and $30^{\text {th }}$ April, 2003 with the objectives to determine the demographic characteristics of blood donors and to find out the frequency of malaria parasites among the blood donors in Dhaka city. An interview schedule was used as research instrument. A pre-tested structured questionnaire was used to collect data through face to face interview with the respondent. The samples were examined under microscope by thick film and confirmed in the laboratory of IEDCR, Dhaka. Thick films were done for the detection of the parasite. The information collected in data collection sheets. Then the data were transferred to the master tabulation sheet after proper checking. Thereafter the data were compiled, processed and analyzed.

\section{Results:}

A total of 400 blood donors were selected for the study. The socio-demographic characteristics of the study subjects show that among 400 blood donors $304(76 \%)$ were male and $96(24 \%)$ of them were female.

\section{Table-I}

Frequency distribution of the responders

\begin{tabular}{|c|c|c|}
\hline Variables & $\begin{array}{c}\text { Professional } \\
\text { donors }(n=200)\end{array}$ & $\begin{array}{c}\text { Voluntary } \\
\text { donors }(n=200)\end{array}$ \\
\hline \multicolumn{3}{|l|}{ Age groups } \\
\hline $20-30$ & 77 (38.5) & $76(38.0)$ \\
\hline $30-40$ & $98(49.0)$ & $84(42.0)$ \\
\hline $40-50$ & $22(11.0)$ & 35 (17.5) \\
\hline $50+$ & 03 (01.5) & 05 (02.5) \\
\hline Mean $\pm \mathrm{SD}$ & $32.55 \pm 5.66$ & $33.45 \pm 5.74$ \\
\hline \multicolumn{3}{|l|}{ Sex } \\
\hline Male & $182(91.0)$ & $122(61.0)$ \\
\hline Female & $18(09.0)$ & 78 (39.0) \\
\hline Male : Female & $10.11: 1$ & $1.56: 1$ \\
\hline \multicolumn{3}{|l|}{ ABO blood group } \\
\hline A & $50(25.0)$ & $62(31.0)$ \\
\hline B & $60(30.0)$ & 78 (39.0) \\
\hline $\mathrm{O}$ & $72(36.0)$ & $44(22.0)$ \\
\hline $\mathrm{AB}$ & $18(09.0)$ & $16(08.0)$ \\
\hline \multicolumn{3}{|l|}{ Rh typing } \\
\hline Positive & $186(93.0)$ & $190(95.0)$ \\
\hline Negative & $14(07.0)$ & $10(05.0)$ \\
\hline \multicolumn{3}{|c|}{ Previous history of malaria } \\
\hline Present & $02(01.0)$ & 06 (03.0) \\
\hline Absent & $198(99.0)$ & $194(97.0)$ \\
\hline \multicolumn{3}{|c|}{ Resident/travel in malarial zone } \\
\hline Yes & $12(06.0)$ & $40(20.0)$ \\
\hline No & $188(94.0)$ & $160(80.0)$ \\
\hline \multicolumn{3}{|c|}{ History of anti malarial drugs } \\
\hline Present & $02(01.0)$ & 06 (03.0) \\
\hline Absent & 198 (99.0) & 194 (97.0) \\
\hline
\end{tabular}

Figure in the parentheses shows the corresponding percentage. 
Prevalence of Malaria Parasites among Blood Donors in Selected Hospitals

Hoque MM et al.

Table-II

Distribution of Blood film examination for malaria

\begin{tabular}{lccc}
\hline $\begin{array}{l}\text { Blood film examination } \\
\text { formalaria parasites }\end{array}$ & $\begin{array}{c}\text { Professional donors } \\
(\mathrm{n}=200)\end{array}$ & $\begin{array}{c}\text { Voluntary donors } \\
(\mathrm{n}=200)\end{array}$ & $\mathrm{p}$ value \\
\hline Found & $04(02.0)$ & $01(0.50)$ & 0.372 \\
Not found & $196(98.0)$ & $199(99.5)$ & \\
\hline Total & $200(100.0)$ & $200(100.0)$ & \\
\hline
\end{tabular}

Figures in the parentheses shows the corresponding percentage.

Considering eligible age of being blood donor 18 year, $24(6 \%)$ were of age group $<21$ year, $124(36 \%)$ were of age group 21-30 years, 192 $(48 \%)$ were of age group 31-40, 56 (14\%) were of age group 41-50 and 8 (2\%) were of age group $>50$ year. Out of 400 blood donors, 112 (28\%) were of A group, 148 (37\%) were of B group, 116 $(29 \%)$ were of O group and $24(6 \%)$ was of $A B$ group. Out of 400 donors, 376 (94\%) were of Rh +ve and $24(6 \%)$ were of $\mathrm{Rh}$-ve. Out of 400 blood donors, the malaria parasites were found by blood film examination in $3(0.76 \%)$ donors and malaria parasite was not found in 393 (99.3\%). Among 400 blood donors, 52 (13\%) donors had the history of residence / travel in malaria zone and $348(87 \%)$ had no such history. Eight $(2 \%)$ out of 400 blood donors had previous history of malaria and 392 (98\%) had no previous history of malaria. Eight $(2 \%)$ out of 400 blood donors had taken anti-malarial drug and 392 (98\%) had not taken any such drug.

\section{Discussion:}

The present study conducted among blood donors attending in the departments of transfusion medicine of BSMMU and NIDCH with the objectives to determine the demographic characteristics of blood donors find out the frequency of malaria parasites among the blood donors in Dhaka city. The ultimate objective of the study was to eliminate professional blood donors, to encourage voluntary blood donation and to ensure safe blood transfusion.

In the present study 400 blood donors attended the transfusion medicine department of BSMMU and NIDCH were considered and evaluated as per various parameters. Most of the results were consistent with various studies both in home and abroad. There were a few inconsistent values too. This variation may be for many reasons and the final comment could be made only after further extensive study on this subject. In the present study the frequency of malaria parasites in blood film was higher than the present status of malaria parasites among the voluntary and professional blood donors after implementation of Safe Blood Transfusion Programme.

In a study by Slinger et al. ${ }^{12}$ it has been estimated that there may be 1 case of malaria contracted through blood transfusion in the United States per 4 million donor units, with a fairly steady incidence of 1-3 cases per year reported by the US Centers for Disease Control and Prevention. In countries where the disease is endemic, there may be more than 50 cases per million donor units. Another study by Busch $^{13}$ estimated the incidence of malaria transmission by blood transfusion is less than that of hepatitis $B$ virus and bacterial infections and is similar to that of hepatitis $\mathrm{C}$ or Human Immunodeficiency Virus after the introduction of Nucleic Acid Testing (NAT) techniques.

Hossain et al. ${ }^{14}$ in a study carried out in Chittagong Medical College Hospital reveals that the blood transfusion transmitted malaria was $0.92 \%$. Two cases of blood transfusion transmitted malaria were found among the family members of army personnel admitted in Combined Military Hospital, Mymensingh ${ }^{15}$.

According to the monitoring report on Safe Blood Transfusion Programme (SBTP), malaria parasites found $0.02 \%$ among the professional blood donors and $0.03 \%$ among the voluntary blood donors ${ }^{16}$. Though the present study 
conducted with small sample size the frequency of malaria parasites was higher than SBTP.

Blood safety is a topic of continuing concern, and much effort is expended on measures to decrease the risk for transmission of infectious agents via transfusion. At the same time, emerging infections may threaten this safety. The risk for major transfusion transmissible infections continues to decline as a result of continually strengthening interventions and because of more general improvements in public health. The estimated risk for transfusion transmitted hepatitis viruses and retroviruses is now vanishingly small, but clinicians should be alert to the possibility of infection with emerging infectious agents, because preventive measures may not be available in all cases ${ }^{17}$.

Among potential screening tests, diagnosis on the basis of a blood-smear examination is not sensitive enough, since donors who have transmitted the infection typically have a low level of parasitemia that may not be detected even by careful examination of a blood smear. In their current stage of development, antigendetection tests have an even higher limit of detection (in terms of the number of parasites per cubic millimeter) than blood-smear examination and would be of limited usefulness in screening.

The study was conducted only on two selected hospitals in Dhaka city of Bangladesh. So generalization of this study could not be made for the whole country. A bigger sample size could reveal more findings. Many of the respondents replied to questions from their memories, which could have led to recall bias.

\section{Conclusion:}

The present study conducted among blood donors attending in the departments of transfusion medicine of BSMMU and NIDCH. Although conducted with a small sample size, the study showed some risk of malarial transmission by the voluntary and professional blood donors. So screening for malarial parasite should be recommended to ensure safe blood transfusion.

\section{References:}

1. Cheesbrough M. District Laboratory Practice in Tropical Countries. Part 1. Cambridge: University Press, 1998.

2. Bruece-Chwatt, LJ. A longitudinal Survey of Natural Malaria Infection in a Group of African Adults. West African Med J. 1963; 12:199-206.

3. Wylie BR. Transfusion transmitted infection: viral and exotic diseases. Anaesthetics and Intensive Care. 1993; 21:24-30.

4. Kitchen AD and Chiodini PL. Malaria and blood transfusion. Vox Sang. 2006; 90(2):77-84.

5. Kinde-Gazard, Oke J, Gnahoui I, Massougbodji A.The risk of malaria transmission by blood transfusion at Cotonou, Benin. Sante 2000; 10: 389-392.

6. Dover AS and Schultz MG. Transfusion Induced Malaria. Transfusion. 1971; 11: 353-357.

7. Chauhan V, Negi RC, Verma B, S Thakur S. Transfusion Transmitted Malaria in a NonEndemic Area. JAPI. 2009; 57:653-654.

8. Uneke CJ, Ogbu O, Vincent Nwojiji V. Potential risk of induced malaria by blood transfusion in South-eastern Nigeria. MJM. 2006 9:8-13.

9. Mungai M, Tegtmeier G, Chamberland M, Parise M. Transfusion-Transmitted Malaria in the United States from 1963 through 1999. N Engl J Med. 2001; 344(26): 1973-1978.

10. Park K. Park's text book of preventive and social medicine. $16^{\text {th }}$ edition. Jabalpur: Banarsidas Bhanot; 1997:162-174.

11. Haque U, Ahmed SM, Hossain S, Huda M, Hossain A, et al. Malaria Prevalence in Endemic Districts of Bangladesh. PLoS ONE. 2009; 4(8): e6737.

12. Slinger R, Giulivi A, Bodie-Collins M, Kain K. Transfusion-transmitted malaria in Canada. CMAJ. 2001; 164(3): 377-379.

13. Busch MP. HIV, HBV, and HCV: new developments related to transfusion safety. Vox Sang. 2000; 78: Suppl 2:253-256.

14. Hossain MA, Mamun AA, Yunus EB, Rahman MR, Faiz MA. Clinical pattern of malaria cases in Chittagong Medical College Hospital, JCMCTA. 1996; 7(S3): 4-15.

15. Hossain SMM, Banu LA, Rahman ASMM. Transfusion transmitted malaria - A case report. BAFMJ. 2000; XXVII (2):55-56.

16. Monitoring report on safe blood transfusion programme (DGHS/UNDP/BGD/97/005). PeriodJanuary, 2001 to September, 2002; 8.

17. Dodd RY. Current risk for transfusion transmitted infections. Current Opinion in Hematology. 2007;14(6):671-676. 